\title{
OCUPACIÓN ANTRÓPICA DE RAMBLAS Y BARRANCOS EN LA COMARCA DEL BAJO SEGURA (ALICANTE): ANÁLISIS-DIAGNÓSTICO DE LA SITUACIÓN EN ALGUNO DE SUS MUNICIPIOS*
}

\author{
Eladio Balboa Zaragoza**
}

\begin{abstract}
RESUMEN
El propósito de este trabajo es mostrar, a partir del estudio de casos concretos, la ocupación antrópica de los cauces en distintos municipios de la Vega Baja del Segura. En estos cauces, se encuentran numerosos puntos conflictivos, en los que lluvias de fuerte intensidad horaria producen pérdidas humanas y daños económicos. Los Planes Municipales de Emergencia, de elaboración obligatoria en municipios de población superior a 2.000 habitantes y solución necesaria para disminuir la siniestralidad de las áreas afectadas, se muestran ineficaces ante su inexistencia, en unos casos, o su no disponibilidad en el propio municipio.
\end{abstract}

Palabras clave: barranco, punto conflictivo, lluvia de fuerte intensidad horaria.

\begin{abstract}
This work purpose is to show, from the concrete cases study, the riverbed occupation on the part of the man in various towns of the Vega Baja of the Segura. In these riverbeds, we find numerous conflictive spots, in these places, strong intensity rain hourly produce human losses and economic damages. Emergency Local Plans, they are necessary solution to reduce the risk in the affected zones and obligatory elaboration in towns with more inhabitants than 2.000, show their inefficiency because of they don't exist or else they are not available.
\end{abstract}

Key words: ravine, conflictive spots, strong intensity rains hourly.

* Esta nota muestra los resultados de la investigación llevada cabo por el autor, entre los meses de julio de 1995 y abril de 1996, y que forman parte de una trabajo de investigación más amplio titulado «Ocupación antrópica de ramblas y barrancos en las tierras meridionales de Alicante» bajo supervisión del profesor Jorge Olcina Cantos.

** Licenciado en Geografía. Universidad de Alicante. 


\section{Introducción}

Los rasgos climáticos, la disposición de estructuras de relieve próximas a la línea de costa y la propia naturaleza de los suelos condicionan el comportamiento enérgico que experimentan los cursos de agua de las tierras mediterráneas ibéricas cuando acontecen episodios de lluvia intensa y abundante.

Ramblas y barrancos tornan, así, de elementos naturales, en amenaza para el hombre cuyas actividades, ajenas al comportamiento del medio físico donde se desarrollan, han ido aumentando la virulencia de sus efectos, en suma, el grado de riesgo ante estos episodios.

Dos son los elementos básicos e integrantes del riesgo de inundación en áreas fluviales mediterráneas: la frecuencia de las lluvias intensas y el grado de ocupación antrópica de los cauces.

En las lluvias mediterráneas, con su comportamiento muy irregular, importan poco frecuencias o períodos de retorno. En los planes municipales de emergencia y planes de ordenación urbanística consultados para elaborar la presente investigación, los redactores se basan regularmente en períodos de retorno de cincuenta años. Por su parte, la Ley de Aguas de 1985 establece un período de retorno de 500 años para considerar un territorio como inundable y, por tanto, con posibilidad de edificar en él.

Por otro lado, la ocupación antrópica de los territorios cercanos a ríos y ramblas en el sureste peninsular se remonta a los primeros asentamientos humanos.

La elección del espacio analizado, el Bajo Segura, se justifica por la importancia económica que tiene en esta comarca la actividad agraria, la más afectada por los procesos de inundación y, al mismo tiempo, los reiterados episodios de lluvias muy intensas que han provocado elevadas pérdidas económicas. Aspectos que han convertido a esta comarca en la más afectada por inundaciones de las tierras alicantinas.

El método de trabajo se ha basado en reconocimientos de campo detallados para la evaluación del grado de ocupación actual de ramblas y barrancos significativos del ámbito de estudio, paso previo a la consulta de documentos de planeamiento municipal y planes municipales de emergencia a fin de constatar las propuestas de ordenación con la realidad presente.

\section{Ocupación antrópica de cauces en algunos municipios del Bajo Segura: análisis- diagnóstico}

\section{Albatera}

\section{A) Puntos conflictivos}

En este municipio se han analizado el barranco, con curso errático, de El Tollo y la rambla de Algüeda

El cauce del barranco del Tollo es difícilmente discernible en la actualidad (ni siquiera mediante la fotografía aérea) porque ha sido ocupado en su práctica totalidad por los cultivos agrarios. Lo único que queda como prueba de que allí existía un barranco es la senda llamada «camino del Tollo». Su disposición teórica sería WNW-ESE, con origen en la Rambla Salada y desembocadura en el propio casco urbano de Albatera. El barranco provoca, con ocasión de lluvias intensas, la inundación de parcelas de cultivo y del barrio de San Francisco, en el noroeste del casco urbano de Albatera (vid. mapa 2).

Al este de Albatera y con una disposición nornoroeste-sureste nos encontramos con la Rambla de la Algüeda que pasa al noroeste del casco urbano, proviene de la Sierra de 


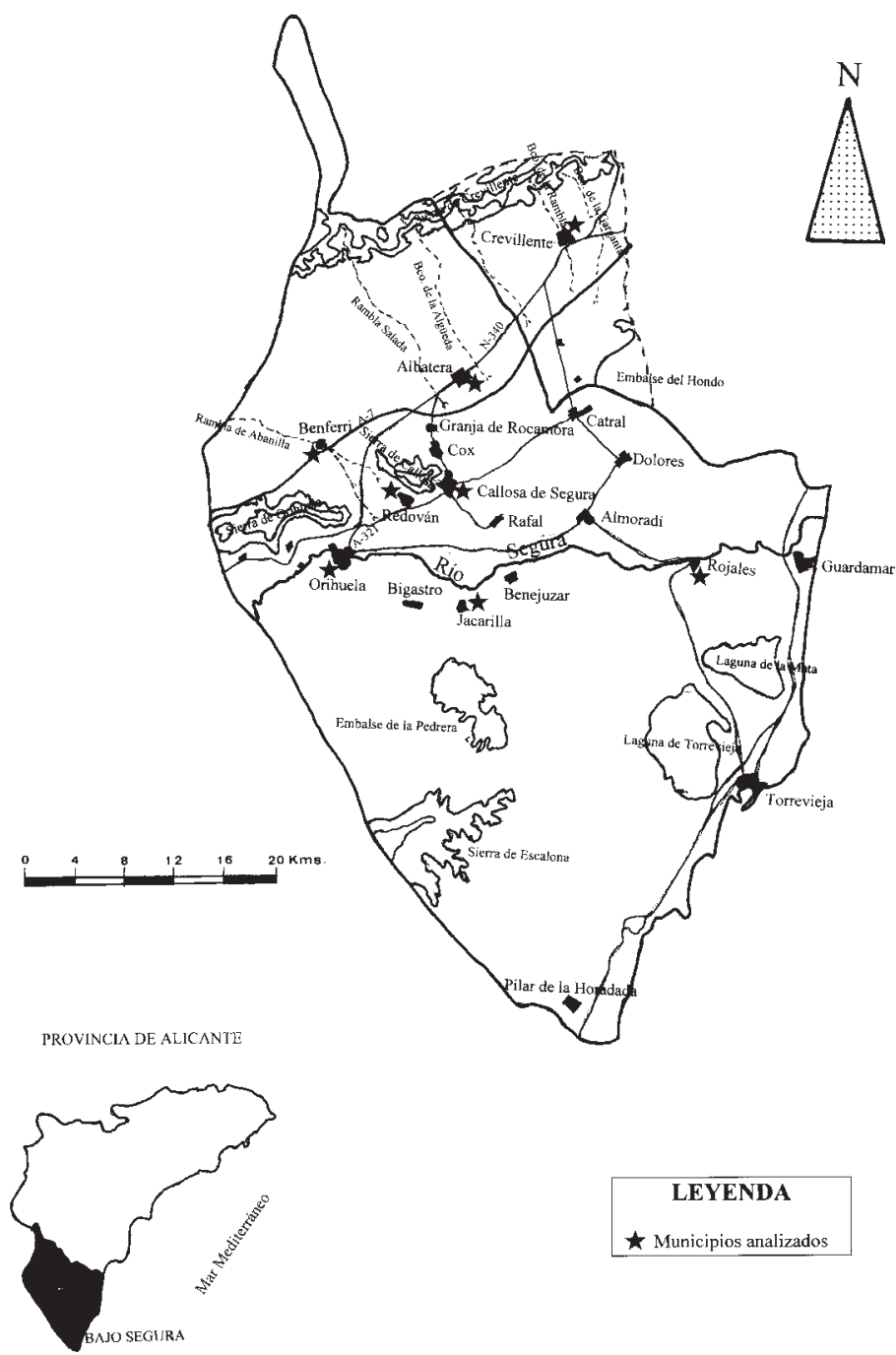

MAPA 1. Localización de municipios y puntos conflictivos analizados.

Crevillente. Esta rambla está encauzada en su tramo más bajo y su curso se difumina en el paraje llamado «El Saladar» de Albatera.

Al norte del núcleo de Albatera, el barranco corta un camino rural asfaltado de 5 metros de anchura desde el norte hacia el sur. El encuentro de este barranco con el llamado «camino del derramador» se efectúa mediante unas entubaciones, cuyos ojos son totalmente insuficientes para evacuar el agua circulante con ocasión de una precipitación intensa. El problema ya fue evidente con motivo de la riada de noviembre de 1987, los tubos quedaron cegados por los materiales arrastrados, convirtiéndose así el camino en rambla esporádica.

En los tramos medio y bajo del barranco de la Algüeda se han realizado dos tipos de construcciones con objeto de aminorar los efectos de las avenidas: 
a) Sucesivos muros de contención en la margen derecha de la rambla (en las proximidades del núcleo de Albatera) que intentan evitar que el agua se desborde. El más moderno de ellos se encuentra a la altura de la N-340 y se construyó con subvención de la Generalitat Valenciana después de las inundaciones de noviembre de 1987 (obras de emergencia).

b) Pequeñas presas para laminar el caudal de agua. A ambos lados de las presas, en el mismo lecho, hay depositados materiales que han sido arrastrados por la corriente afianzados por una malla metálica. De manera que, con una fuerte riada, abundantes arrastres por la corriente.

A ello se suma una pequeña presa y que, antiguamente, se utilizaba para desviar el agua hacia las parcelas colindantes (riego de turbias).

B) Medidas de defensa ante inundaciones

El Ayuntamiento de Albatera no posee ningún tipo de plan frente a inundaciones.

Las Normas Subsidiarias de Albatera establecen 15 metros ambos lados del cauce como zona de servidumbre, es decir, como zona de uso público. Este punto de la ley es totalmente desatendido en varios casos.

Se ha habilitado una Zona Urbana Industrial que limita en una parte con el margen izquierdo de la Rambla Salada (vid. mapa 2), en su tramo más bajo. Este espacio industrial se proyectó con vistas a aprovechar la posición ventajosa que ofrece el trazado de las carreteras A-321 y la Nacional 340 (a la que corta el barranco). Un amplio sector de la Zona Urbana Industrial «Mos Del Bou» no respeta la zona de servidumbre.

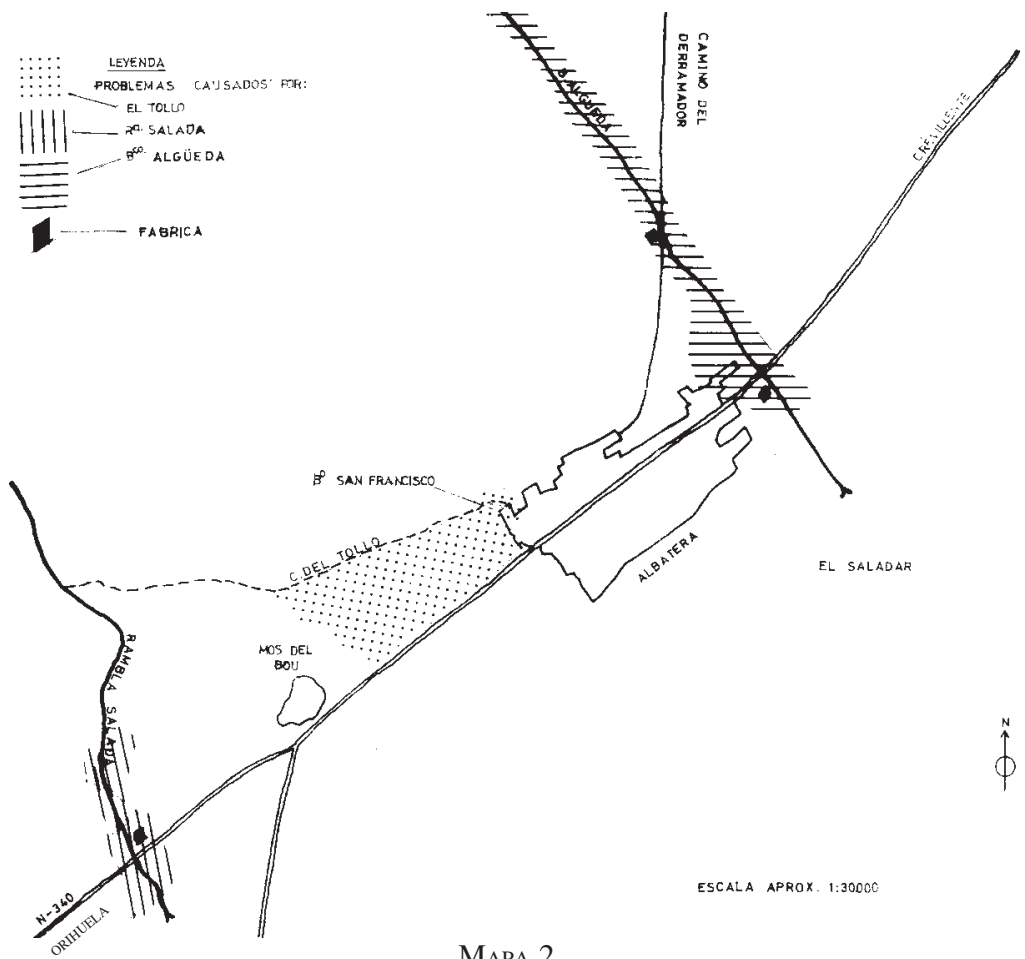

MAPA 2 
A lo largo de todo el tramo medio-bajo de la rambla de la Algüeda, la zona de servidumbre no es respetada y el barranco se ve encajonado por parcelas de cultivo a ambos lados del barranco, incluso se han observado nuevas roturaciones en el propio cauce. En esta misma rambla las Normas Subsidiarias no son respetadas también por dos casos concretos, se trata de dos naves fabriles. Una de ellas está situada muy cerca del camino del Derramador, a un kilómetro al norte de Albatera. La otra se encuentra en el tramo bajo, al lado de la N-340, también pegada al casco urbano pero fuera de la zona establecida como suelo urbanizable.

El mismo barranco del Tollo, como se ha señalado, ha desaparecido como consecuencia de su ocupación por parte de parcelas, claro que esta ocupación se llevó a cabo antes del establecimiento de las leyes actuales.

\section{Callosa de Segura}

\section{A) Puntos conflictivos}

Esta población asentada en las faldas de la sierra de Callosa es atravesada por la Rambla de la Plana, conocida, en el pueblo, como la «Rambla».

En la actualidad, este barranco sólo mantiene su cauce en su tramo más alto, que se pierde con posterioridad en el callejero callosino: calle de la Cantera, barranco Tatus, calle del Pilar, Rambla Alta y Rambla Baja. Esta ocupación antrópica del curso fluvial llegó hasta el punto de la construcción, en el sector de la Rambla Baja, de un conjunto de casas que impedían totalmente la circulación de agua y que fueron derribadas la década pasada.

En la zona más alta del núcleo urbano, en el barrio del Pilar, las casas están elevadas (zócalo) respecto de la calle para evitar que entre agua a las viviendas. Además están separadas de la rambla por un canalillo, a ambos lados de la calle Rambla Alta, que recoge agua, aunque en caudal muy limitado.

Con motivo de las inundaciones ocurridas en noviembre de 1987, los diques, situados en el tramo más alto del barranco, se rompieron. Ello provocó un enorme arrastre de materiales que creó un caos en el casco urbano. Se paralizó la circulación a lo largo de toda la Rambla Alta y Rambla Baja (eje del casco urbano) y se destruyeron más de cincuenta vehículos (enterrados bajo el material que arrastró el agua). Este material llegó a tener, en algunos puntos, más de metro y medio de altura, hubo destrozos en el asfalto, en el alcantarillado y en numerosas viviendas.

Las ayudas post-inundación de la Generalitat Valenciana, propiciaron la construcción de unos diques más resistentes y con aberturas para dejar pasar el agua, además los sedimentos del lecho se afianzaron con grandes rocas y cemento. De cualquier manera, aún no se ha dado ningún episodio de lluvias lo suficientemente intensas como para comprobar la eficacia de esta nueva infraestructura.

En este municipio, un segundo punto conflictivo se sitúa en la carretera A-321, (vid. mapa 1) a la altura de la antigua «cantera del Tío Pertusa» situada en la parte más baja de la sierra, al sur de la misma. Cuando las lluvias son importantes se producen arrastres de materiales, desde dicha cantera y a través de la calle Grupo del Almendro que llegan hasta la carretera dificultando el tráfico rodado.

Por último, un tercer punto conflictivo dentro de este término municipal, se ubica en la misma carretera A-321 en dirección Redován cerca del cementerio de Callosa, unos trescientos metros al oeste del anterior. Es la zona conocida «Rabosero», que con motivo de lluvias intensas también aporta numerosos materiales al asfalto de la carretera creando idénticos problemas que el sector de la «cantera del Tío Pertusa». 
B) Medidas de defensa ante inundaciones

Este municipio tampoco posee ningún plan de emergencia o similar frente al riesgo de inundaciones. Como se ha señalado, los riesgos para la población no son tanto de inundación como de arroyada la cual ha provocado grandes destrozos en el casco urbano.

Las casas a ambos lados de la rambla incumplen totalmente la normativa que establece las ley de aguas pero la antigüedad de las mismas hace imposible su desalojo. Este barranco ha pasado a formar parte integrante del callejero callosino.

Los problemas planteados en los lugares «Cantera del Tío Pertusa» y «el Rabosero» que llegan a impedir el tráfico en la comarcal, A-321, reclaman el desvío de dicha carretera.

\section{Crevillente}

\section{A) Puntos conflictivos}

Por su situación, en la falda de la enorme mole subbética que lleva su nombre, Crevillente sufre problemas de avenidas de agua cada vez que los cursos intermitentes que bajan desde la sierra se ponen en funcionamiento con motivo de lluvias de fuerte intensidad horaria. Muchas de sus calles sólo son continuación de torrenteras, ramblizos y barrancos. Por ello, y al igual que ocurre en Callosa de Segura o Redován, estas calles se convierten en cauce para las aguas. De este modo, el buen funcionamiento del alcantarillado es básico para evitar problemas en el casco urbano.

Como rasgo general, el núcleo de Crevillente no sufre inundaciones graves puesto que el agua que discurre por su callejero no se estanca hasta llegar al sector de El Hondo. Los problemas de inundaciones ocurren pues fuera del casco urbano, en las partidas rurales de San Felipe de Neri, las Casacas, el Realengo y el Rincón de Pablos.

Entre los numerosos problemas que afectan a los distintos barrancos que atraviesan el término municipal de Crevillente, destacan:

- Escasa luz en los puentes de los barrancos que atraviesan la Carretera Nacional 340. Esto afecta a los barrancos de: La Rambla, La Garganta, Amorós, Peña Sendra, El Hondo, San Cayetano y El Pollo.

- Acumulación abundante de residuos (provenientes, en su mayoría, del polígono Industrial Sur) que afecta sobre todo al barranco de La Rambla.

- Utilización del lecho del barranco como camino rural para acceder a las parcelas de cultivo, parcelas que en muchos casos ocupan los márgenes o el propio lecho del cauce. Resulta afectado por esto el barranco de La Rambla.

- Inutilización del camino Colorada con motivo de intensas lluvias y provocada por el barranco de La Rambla.

- Inundación del camino de La Mangranera. Hecho provocado por los barrancos de La Rambla y El Hondo.

- Inutilización del camino de Carga causada por los barrancos de Amorós y San Cayetano.

- La estructura que soporta el canal de Albatera ciega el paso del agua. Problema que se plantea exclusivamente en el barranco de El Hondo.

B) Medidas de defensa ante inundaciones

El PGOU vigente en Crevillente establece 50 metros a ambos lados de cualquier cauce, 
que discurra por su término municipal, como zona inundable y, por tanto, de uso público según la Ley de Aguas de 1985. Esta es la primera normativa transgredida en Crevillente. A lo largo de todo el recorrido la invasión de la zona inundable, por parte del hombre, queda bien patente: fábricas, viviendas agrícolas, parcelas de cultivo.

Este municipio posee un plan redactado por la Consellería: Plan Básico Municipal para la lucha contra las inundaciones en el municipio de Crevillente. La primera parte de este plan está dedicada íntegramente a repartir las funciones en caso de emergencia desde al Alcalde hasta a la Brigada de Obras y Jardines, pasando por: el Teniente de Alcalde, el Concejal de Obras Públicas y Urbanismo, el Jefe de Policía, el Arquitecto, el responsable jurídico, etc...

Todo ello muy importante en caso de emergencia, pero lo que realmente interesa, a efectos de ordenación territorial, es una serie de aspectos interesantes sobre los que el plan llama la atención, por ejemplo, además de mencionar la inutilización temporal de teléfonos y telégrafos se establece el sector norte como zona de riesgo medio debido al mal estado general de las casas. El mal estado general de las casas continua por lo que el riesgo en ese sector aún no se ha evitado.

El mismo Plan establece que las primeras medidas que deberían adoptarse serían:

a) Limpieza y acondicionamiento periódico de todos los cauces del municipio. Algo que está establecido en la mayoría de las localidades pero que raramente se cumple, los cauces de Crevillente están sucios desde hace varios años.

b) La canalización de barrancos y la construcción de pequeños embalses en los tramos altos de los barrancos para laminar las aguas. Las canalizaciones no deben de ser una solución general, sólo deben ser utilizadas para casos concretos. Desde luego, la construcción de embalses en cabecera permite frenar la velocidad del agua y para evitar riesgos es una buena solución pero estas pequeñas presas aún no han sido construidas.

c) Estudio de los puntos conflictivos y

d) Estudiar la problemática en San Felipe de Neri, Las Casicas, el Rincón de Pablos y el Realengo.

Es decir, un plan de riesgos frente a inundaciones recomienda estudiar estos casos concretos pero no establece ninguna actuación a corto o medio plazo cuando los habitantes de estas pedanías están expuestos a un alto riesgo.

\section{Orihuela}

\section{A) Puntos conflictivos}

Se trata de un municipio que ha sufrido especialmente los efectos de las inundaciones por verse atravesado de oeste a este por el río Segura y, además, su casco urbano también se ve seriamente dañado, con motivo de fuertes lluvias, por el discurrir de agua por barrancos que vienen de la Sierra de Orihuela, al norte del municipio. Por otro lado, tiene problemas con otros cauces de agua intermitentes como es el caso de la Rambla de Abanilla, aunque éste no repercute gravemente en el casco urbano sino en sus pedanías de El Escorratel o Arneva que además sufre las avenidas de los barrancos que provienen de la Sierra del Cristo.

Los distintos barrancos y ramblas del término de Orihuela afectan sobre todo a las diferentes pedanías y distintas zonas del casco urbano de Orihuela. Los puntos conflictivos de riesgo ante avenidas e inundaciones se resumen en los siguientes: 
- La pedanía de La Aparecida se ve afectada por la Rambla del Muerto-La Muda.

- El Raiguero de Bonanza se ve afectado por el barranco que tiene el mismo nombre y por el Barranco del Pinar de Bonanza.

- El barrio de San Isidro se ve afectado por distintos barrancos menores, desembocan en la calle Salida al Río.

- Los Barrancos de la Sierra de San Miguel inundan las calles: Capuchinos, San Francisco, Lepanto y otras e igualmente desembocan en la C/ Salida al Río.

- La calle Ros y la Plaza Monserrate se ven inundadas por el Barranco de la Sierra de San Miguel que desemboca en la C/ Salida al Río.

- El Barranco Pocico de Santiago inunda Pocico de Santiago, calle del Hospital (al tener que evacuar el agua por una alcantarilla inadecuada), calle Santiago y plaza Santiago (en este punto la calle queda completamente bloqueada).

- Con menor gravedad, la calle y plaza de Santa Lucía presenta problemas causados por los barrancos que van al Barrio Nuevo, desaguando al Río por viejas alcantarillas.

- Los Barrancos de la Calle Arriba inundan diferentes calles, las más importantes son: C/ Miguel Hernández, La Cruz, Adolfo Clavarana y Calvo Sotelo.

- Los Barrancos de San Antón inundan el barrio con el mismo nombre y todo el palmeral.

— El Barranco de Timor inunda este callejón, Doctor Sarget, Calle Mayor, etc...

- La Rambla de Abanilla inunda el Escorratel, carretera de Benferri, Puente Alto, Camino Viejo de Callosa, La Campaneta, Badén y Mudamiento.

- Mención aparte se merece la carretera Nacional 340, que a su paso por Orihuela puede verse cortada por los desbordamientos de la Rambla del Muerto-La Muda, Barranco del Raiguero de Bonanza, Barranco del Pinar de Bonanza y la propia Rambla de Abanilla.

También al igual que ocurría en Crevillente, pero aquí en mayor medida, las acequias y azarbes pueden provocar inundaciones. Los más importantes que se destacan en el plan de Protección Civil son las siguientes: azarbe Mayor de Hurchillo, acequia de Alquibla, acequia de Molina, acequia de los Huertos, acequia de las Puertas de Murcia, acequia de Almoradí, acequia de Callosa y acequia del Escorratel.

Por supuesto el factor de riesgo en Orihuela es el propio Río Segura. Los distintos embalses y presas que hay en la cuenca alta del Río no son suficientes para evitar los desbordamientos del Segura a su paso por Orihuela. El crecimiento del nivel del Río solía ser lento antes de su encauzamiento debido a una serie de factores (escaso desnivel Orihuela, Guardamar, numerosos meandros, abundante vegetación,...) pero aún Protección Civil destaca los siguientes puntos de taponamiento del Río en el término de Orihuela:

a) Molino de la Ciudad.

Era provocado cuando los ojos del puente se cegaban a causa de la acumulación de cañas, barro y otros objetos.

b) Puente de Levante.

En este lugar el taponamiento se producía por cañas que retenían todo el material que pudiera arrastrar el agua.

En teoría estos problemas han desaparecido como consecuencia de las obras de encauzamiento del Río, pero, como ya hemos comentado, desde que se llevó a cabo esta infraestructura no ha habido ningún episodio de lluvias de suficiente intensidad horaria como para demostrar la eficacia de las obras. 
c) La desembocadura del Río.

A pesar de que esté fuera del término de Orihuela, hay que destacar la desembocadura del río Segura en Guardamar como factor a tener en cuenta en las inundaciones debido a que las olas del mar con motivo de viento de Levante impiden un correcta salida del agua del Río y todos los desperdicios que arrastra, hecho que repercute en todo el tramo bajo del Río Segura.

Antes del encauzamiento del Segura, también se establecieron los puntos problemáticos en cuanto a posibles desbordamientos se refiere. Las obras en el río deberían de haber acabado con los siguientes problemas:

\section{Las Norias.}

Rotura o desbordamientos en el km. 3 de la carretera de Beniel (A-330) en el Rincón de Ortuño. También afecta a viviendas diseminadas y explotaciones de la zona.

\section{Acequia de Alquibla.}

Rotura o desbordamiento en la misma afectando a casas diseminadas y a Las Norias.

3. Puente del Trasvase.

La rotura (margen derecha) en este lugar afecta a explotaciones, viviendas y la carretera entre Orihuela y Beniel (A-330).

\section{Molino de la Ciudad.}

Desbordamiento en la margen izquierda, producido por el taponamiento antes resaltado, inundando la barriada y casas diseminadas.

5. Cruz del Río.

Inundación del Camino de Enmedio causada por el Azarbe Menor de dicho lugar.

6. Salida al Río (detrás del Niño Simón).

Al entrar el agua del Segura por una serie de barrancos de la margen izquierda, se inunda todas las calles donde desembocan éstos: Salida al Río, Gloria, y Barranco.

\section{Azarbe Las Lavanderas.}

Produce la inundación del Senda del Obispo, Mota del Río y Carretera A-330.

8. Riacho y fábrica de hielo.

A través de estos dos lugares se inundan las siguientes calles: Riacho, San Pascual, Pedro Maza, Plaza Nueva, Sor Patriciniovives, La Sal y Calderón de la Barca.

9. Rincón de Calle Paradas.

Por este punto (margen derecha) se inundan las calles Paradas y Obispo Rocamora.

10. Barrio de San Pedro.

En la margen izquierda del Segura. Es un sector a menor altitud y por ello se inundan varias viviendas. Solamente con barreras se evita la total inundación del Barrio de Los Huertos. 


\section{Puente de Hierro.}

La mota en su margen izquierda está muy debilitada, por ello hay riesgo en las viviendas de la zona.

\section{Acequia de los Huertos.}

Cuando se desborda afecta a zonas de huerta y, como mucho a la población de Molins.

B) Medidas de defensa ante inundaciones

Orihuela cuenta con un Plan de Emergencia Municipal de Avenidas del Río Segura redactado por Protección Civil de Orihuela, a principios de los noventa y que establece una serie de puntos conflictivos que ya hemos visto en el apartado anterior.

Los problemas en los barrancos y ramblas no han sido resueltos. Todavía no se ha actuado en ellos, ni siquiera en la Rambla de Abanilla que es la que produce más problemas en este sector.

A su paso por Orihuela el río Segura ha sido encauzado (Plan de Defensa ante inundación del Segura). Ante la ausencia de episodios de lluvias intensas ocurridas desde 1989 es imposible prever si esta infraestructura será suficiente para evitar problemas en el casco urbano de Orihuela.

\section{Otros ejemplos}

También hemos tenido la ocasión de estudiar la documentación referente a los riesgos de inundación de otros municipios de la Vega Baja. El motivo de colocarlos separados ha sido la menor información recogida respecto a los tres municipios ya estudiados.

\section{Benferri}

Esta pequeña localidad de la Vega Baja no posee plan de emergencia, aunque la ley no se lo exige ya que tiene menos de 2.000 habitantes.

Benferri no se trata de una localidad las leyes de una forma demasiado grave. Quizá la excepción sea el barrio llamado «El Cabezo» que no respeta los 15 metros que establece el ordenamiento urbanístico de esta localidad a ambos lados de la rambla de Abanilla como franja de uso público. Aunque, de todos modos, en el tramo donde se encuentra el pequeño número de casas de este barrio el lecho de la rambla es muy ancho y, además, las viviendas se encuentran en la falda de una pequeña elevación, de donde toma su nombre el barrio, así, los problemas que puede sufrir los habitantes del lugar no han de ser demasiado graves.

\section{Rojales}

Es uno de los municipios, junto a Crevillente y Orihuela, que cuenta con un estudio de Consellería en el municipio ante el posible peligro de inundaciones. Este estudio tiene como nombre Plan Básico Municipal contra el riesgo de inundaciones del municipio de Rojales (Alicante), fue redactado hacia 1988 por la Consellería d'Administració Pública de la Generalitat Valenciana.

Uno de los elementos claves del mismo es el del establecimiento de actuaciones en caso de fuertes lluvias. Como es lógico la eficacia del plan no se puede constatar, en este aspecto ni en ningún otro, hasta que no suceda un episodio de lluvias muy intensas. De este 
modo, sólo se puede especular sobre la oportunidad o no del encauzamiento del río y si los problemas de desbordamiento del mismo han sido corregidos.

Lo que es más seguro es que los problemas de avenidas se van a seguir produciendo en casi todo el sector de casco urbano que se encuentra al norte del Río, ya que en este caso la mayoría de las ramblas están totalmente insertadas en la trama callejera.

\section{Jacarilla}

Por su cercanía al río Segura los problemas de inundaciones han sido una constante en el municipio. Desde el norte del casco urbano hasta el borde sur del término municipal es una zona inundable. El núcleo habitado está protegido por un muro de contención. Al sur del término municipal hay inundaciones esporádicas en los cultivos a causa de los barrancos. En el Estudio antes referido se establece que en la zona de Vegas se debe limitar la edificación ante el riesgo de inundaciones. Asimismo, se establece que la zona inundable es suelo protegido por su valor como regadío tradicional y para limitar al máximo las construcciones. Es decir, esta zona se quiere proteger de edificaciones, no por el riesgo de inundaciones sino para preservar la zona de cultivo.

Este pequeño municipio no posee ningún plan de emergencia frente a inundaciones aunque posee un Estudio de Impacto Ambiental. Fue aprobado a finales de octubre de 1992 para ser enviado a Consellería con el fin de que se redactara el consiguiente plan de emergencia frente a inundaciones. Este estudio fue redactado por un Arquitecto con la colaboración de un Ingeniero Técnico Agrícola, un aparejador y un Ingeniero Técnico de Obras Públicas. Por tanto se trata, a nuestro parecer, de personal muy cualificado para muchas cosas pero no para redactar un estudio de este tipo. Un estudio al que casi sólo aportan datos climáticos, geológicos, de calidad de aguas, evolución de la población, etc...

La mitad de este estudio es un resumen de la Normas Subsidiarias. Estas establecen $20 \mathrm{~m}$. a ambos lados del eje de los cauces públicos para poder construir, salvo en aquellos lugares donde la construcción de un muro de contención permita construir más cercanamente.

\section{Redován}

Es uno de los núcleos de la Vega Baja que con mayor frecuencia ha sufrido las consecuencias de las lluvias de fuerte intensidad horaria y de las inundaciones asociadas a ellas. Por su término municipal atraviesa la Rambla de Redován pero ésta no es la causante de los mayores destrozos puesto que se encuentra encauzada desde Benferri y además no baja demasiada agua ya que la mayoría fluye por el aliviadero hacia la rambla de Abanilla, que es la que provoca los problemas en el término municipal de Redován: en el Campo, la Huerta, el propio núcleo habitado y zonas ajardinadas al sur del anterior.

La mitad sur del casco urbano se ve afectado por las inundaciones pero la mitad norte, que se encuentra situado en la falda de la Sierra de Callosa, no se escapa de los problemas puesto que hay, al menos, tres pequeños barrancos que bajando de la sierra se pierden entre el callejero del pueblo. Estos barrancos acarrean problemas por los materiales que arrastran y que conducen hasta las calles de Redován provocando desperfectos en el pavimento y en viviendas.

\section{Conclusiones}

Un aspecto que ha demostrado el trabajo de campo, y al que se ha hecho alusión 
ANÁLISIS-DIAGNÓSTICO DE LA OCUPACIÓN ANTRÓPICA DE RAMBLAS Y BARRANCOS EN ALGUNOS MUNICIPIOS DEL BAJO SEGURA (ALICANTE)

\begin{tabular}{|c|c|c|c|}
\hline LOCALIDAD & $\begin{array}{c}\text { PUNTO } \\
\text { CONFLICTIVO }\end{array}$ & OCUPACIÓN & $\begin{array}{c}\text { PLAN DE } \\
\text { EMERGENCIA } \\
\text { EN EL } \\
\text { MUNICIPIO }\end{array}$ \\
\hline ALBATERA & $\begin{array}{l}\text { - N-340, km. } 34,5 \\
\text { - Corte Derramador con Ram- } \\
\text { bla Algüeda } \\
\text { - Sureste Casco Urbano } \\
\text { - } \text { B }^{\circ} \text { San Francisco } \\
\text { - Sector sur camino Tollo }\end{array}$ & $\begin{array}{l}\text { - Zona Urbana Industrial Mos } \\
\text { del Bou } \\
\text { - Carretera asfaltada } \\
\text { - Nave Fabril } \\
\text { - Viviendas } \\
\text { - Parcelas de cultivo }\end{array}$ & NO \\
\hline BENFERRI & $\begin{array}{l}\text { - El Cabezo } \\
\text { — Bifurcación de la Rambla de } \\
\text { Abanilla }\end{array}$ & $\begin{array}{l}\text { - Viviendas } \\
\text { — Cementerio }\end{array}$ & NO \\
\hline $\begin{array}{l}\text { CALLOSA } \\
\text { DE SEGURA }\end{array}$ & $\begin{array}{l}\text { - La «Rambla» } \\
\text { - «Rabosero» } \\
\text { — Cantera del Tío Pertusa }\end{array}$ & $\begin{array}{l}\text { - Viviendas y calles } \\
\text { - Cementerio y A-321 } \\
\text { - A-321 }\end{array}$ & NO \\
\hline ROJALES & $\begin{array}{l}\text { - Amplios sectores del caso ur- } \\
\text { bano }\end{array}$ & — Viviendas y callejero & SÍ \\
\hline CREVILLENTE & $\begin{array}{l}\text { - Pedanías } \\
\text { - Industrial Sur } \\
\text { - Casas entre el Boch y Ram- } \\
\text { bla, altura del cementerio } \\
\text { - Camino Colorada } \\
\text { - A-7 } \\
\text { - N-340 } \\
\text { - Acceso a A-7 } \\
\text { - Camino Carga } \\
\text { - Camino La Mangranera }\end{array}$ & $\begin{array}{l}\text { - Viviendas } \\
\text { — Naves fabriles y desperdicios } \\
\text { - Viviendas y parcelas de cul- } \\
\text { tivo } \\
\text { - Canalización insuf. } \\
\text { - Escasa luz de puentes sobre } \\
\text { varios barrancos } \\
\text { - El asfalto impide paso del } \\
\text { agua } \\
\text { - Camino sobre antiguo cauce } \\
\text { - Ídem }\end{array}$ & SÍ \\
\hline ORIHUELA & $\begin{array}{l}\text { - Pedanías } \\
\text { - Las Norias } \\
\text { - Acequia de Alquibla } \\
\text { - Puente del Trasvase } \\
\text { - Molino de la Ciudad } \\
\text { - Cruz del Río } \\
\text { - Salida al Río } \\
\text { - Azarbe Las Lavanderas } \\
\text { - Riacho y fábrica de hielo } \\
\text { - Rincón de Calle Paradas } \\
\text { - Barrio de San Pedro } \\
\text { - Puente de Hierro } \\
\text { - Acequia de los Huertos }\end{array}$ & $\begin{array}{l}\text { - Viviendas y calles } \\
\text { - Carretera A-330 km 3, vi- } \\
\text { viendas y parcelas de cultivo } \\
\text { - Casas diseminadas } \\
\text { - Parcelas, viviendas y A-330 } \\
\text { - Barriada y casas disemina- } \\
\text { das } \\
\text { - Camino } \\
\text { - Calles } \\
\text { - Calles y A-330 } \\
\text { - Calles } \\
\text { - Calles } \\
\text { - Viviendas } \\
\text { - Viviendas } \\
\text { - Parcelas de cultivo }\end{array}$ & SÍ \\
\hline JACARILLA & — Rambla del Derramador & - Casco urbano y C-3323 & $\begin{array}{l}\text { Sólo estudio } \\
\text { preliminar }\end{array}$ \\
\hline REDOVÁN & $\begin{array}{l}\text { - La Huerta y El Campo } \\
\text { - Todo el sector norte del cas- } \\
\text { co urbano } \\
\text { - Sector sur }\end{array}$ & $\begin{array}{l}\text { - Parcelas de cultivo } \\
\text { - Viviendas y callejero } \\
\text { - A-321 y jardines }\end{array}$ & NO \\
\hline
\end{tabular}


reiterada en el texto, es el escaso cumplimiento por parte de los Ayuntamientos del artículo número 6 de la Ley de Aguas de 1985 en el que se puede leer lo siguiente:

Las márgenes están sujetas, en toda su extensión longitudinal:

a) A una zona de servidumbre de 5 metros de anchura, para uso público que se regulará reglamentariamente.

b) A una zona de policía de 100 metros de anchura en la que se acondicionará el suelo y las actividades que se desarrollen.

Por supuesto los Planes Generales de Ordenación Urbana, o las Normas Subsidiarias en su caso, de todos los Ayuntamientos contemplan estas disposiciones legales, pero en la práctica esta limitación de usos se ve contrarrestada por apropiaciones indebidas, construcciones «ilegales», asentamientos incorrectos, etc... Como indica Vera Rebollo ${ }^{1}$ los PGOU deben de servir directa o indirectamente para proteger el cauce y las zonas aledañas. Pero los Ayuntamientos siguen siendo permisivos en muchos casos y en otros ellos mismos son los responsables de habilitar zonas susceptibles de inundación como zonas urbanizables, o incluso como Zona Urbana Industrial (Albatera).

Un aspecto curioso es que la mayoría de los Ayuntamientos (Benferri, Albatera, Crevillente...) han ampliado la zona de servidumbre pero aun así, como ya se ha mencionado, el cumplimiento de la misma es muy escaso. En el PGOU de Crevillente se establecen 50 metros a ambos lados del barranco como zona no edificable, pero el incumplimiento de esta norma es manifiesto.

La práctica totalidad de los cauces analizados se encuentran constreñidos por bancales a ambos lados del cauce. Este es un problema grave pero existe otro peor: este constreñimiento, lejos de mejorar, se está agudizando cada vez más a causa de nuevas roturaciones. De este modo se puede repetir lo que ha sucedido en el barranco del Tollo en Albatera (el cual ya hemos tratado anteriormente).

Además las referencias contenidas en las memorias de los PGOU al problema de las inundaciones son mínimas, sólo establecen los márgenes a ambos lados del eje de las ramblas para poder construir, además esta normativa apenas se cumple en algún municipio.

Otro asunto que hay que abordar es el referido al de los Planes de Emergencia Municipal. En ninguno de los Ayuntamientos visitados de la Vega Baja poseen este documento a pesar de que la ley exige a los municipios de más de 2.000 habitantes poseer algún tipo de plan frente a los riesgos que pueda sufrir el término municipal de cada uno; por supuesto, saben de su existencia (en algún Ayuntamiento, ni siquiera eso) pero nada más. ¿Cómo podrá llevarse a cabo una acción rápida y efectiva, por parte de las autoridades, en caso de una catástrofe si los planes de los que se tienen que valer los municipios para ello están en un archivo en Valencia?

El Plan PREVIMET'95, señala que estos planes deben de estar en manos de los alcaldes, como máxima autoridad de Protección Civil en cada Ayuntamiento, «para poder ser aplicado en cualquier momento». Por tanto el Previmet, elemento básico para evitar los daños producidos por las lluvias intensas, tiene fallos de raíz a la vista de lo señalado en el presente escrito.

1 Vera Rebollo, F.: «Protección de cauces en el planeamiento urbanístico y la ordenación del territorio: Estado de la cuestión a través del caso alicantino», en Avenidas Fluviales e inundaciones en la cuenca del Mediterráneo. Instituto Universitario de Geografía de la Universidad de Alicante y Caja de Ahorros del Mediterráneo, Alicante, 1989, pp. 565-574. 
Crevillente y Orihuela son los únicos municipios que tienen un plan especial frente a inundaciones. Rojales también tiene un pequeño estudio referido a esta cuestión. Jacarilla sólo dispone de un estudio de impacto medioambiental. Los demás Ayuntamientos no poseen en sus dependencias ningún documento relativo a la defensa ante lluvias torrenciales e inundaciones, aspecto insólito a la vista de los efectos de los episodios que han afectado a esta comarca en la década de los ochenta (vid. Tabla I).

\section{Bibliografía}

BOX AMORÓS, M. y MORALES GIL, A. (1993): «Barrancos y ramblas: su incorporación al entramado urbano en el sureste peninsular», en Investigaciones Geográficas $\mathrm{n}^{\circ} 11$. Instituto Universitario de Geografía. Universidad de Alicante, pp. 153-169.

DIRECCIÓN GENERAL DE PROTECCIÓN CIVIL (1992): Legislación Básica sobre Protección Civil en España, Madrid.

GONZÁlEZ PÉREZ, J.; TOLEDO, J. y ARRIETA, C. (1987): Comentarios a la ley de aguas. Civitas. Madrid.

MORALES GIL, A.; BOX AMORÓS, M. y MARCO MOLINA, J.A. (1989): «El aprovechamiento de las aguas de avenida: Derecho consuetudinario y disposiciones legales», en Avenidas fluviales e inundaciones en la cuenca del Mediterráneo. Instituto Universitario de Geografía de la Universidad de Alicante y Caja de Ahorros del Mediterráneo, Alicante.

OLCINA CANTOS, J. (1994): Tormentas y granizadas en las tierras alicantinas. Instituto Universitario de Geografía, Universidad de Alicante, 1994.

VERA REBOLLO, F. (1989): «Protección de cauces en el planeamiento urbanístico y la ordenación del territorio: Estado de la cuestión a través del caso de Alicante», en Avenidas fluviales e inundaciones en la cuenca del Mediterráneo. Instituto Universitario de Geografía de la Universidad de Alicante y Caja de Ahorros del Mediterráneo, pp. 565-574. 